\title{
Immunomodulator use in paediatric severe sepsis and septic shock
}

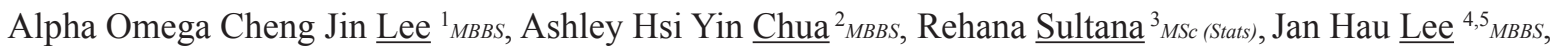
Judith Ju Ming Wong ${ }^{4,5}{ }_{M B B C h} B A O$

\begin{abstract}
Introduction: The use of drugs that modulate the immune system during paediatric severe sepsis and septic shock may alter the course of disease and is poorly studied. This study aims to characterise these children who received immunomodulators and describe their clinical outcomes.

Methods: This is a retrospective chart review of patients with severe sepsis and septic shock admitted into the paediatric intensive care unit (PICU). Clinical, haematological and outcome characteristics of patients with or without exposure to immune-modulating drugs were compared. Primary outcome was PICU mortality; secondary outcomes were 28-day ventilator-free days (VFD) and intensive care unit-free days (IFD). Univariate and multivariable analyses were performed for these outcomes.

Results: A total of 109 patients with paediatric severe sepsis or septic shock were identified. Of this number, $47(43.1 \%), 16(14.7 \%)$ and $3(2.8 \%)$ patients received systemic corticosteroids, intravenous immunoglobulins and granulocyte colony stimulating factor, respectively. Patients who received immune-modulating drugs were more likely to require invasive ventilation (38/54 [70.4\%] versus 26/55 [47.3\%], $P=0.019)$ compared to those who did not. PICU mortality was indifferent between the 2 groups (20/54 [37.0\%] vs $11 / 55$ [20.0\%], $P=0.058)$ even after accounting for chronic complex conditions and admission organ dysfunction (PELOD score) (adjusted odds ratio 1.90, confidence interval [0.72-5.01], $P=0.193)$. However, VFD (19.5 [0-28] vs $25[12-28]$ days, $P=0.038)$ and IFD $(15[0-24]$ vs 22 [9-26] days, $P=0.024)$ were decreased in the immunomodulator group compared to the non-immunomodulator group.

Conclusion: Immune-modulating drugs were frequently used in paediatric severe sepsis and septic shock. Patients who received these drugs seemed to require more PICU support. Further studies are required to examine this association thoroughly.
\end{abstract}

Ann Acad Med Singap 2021;50:765-72

Keywords: Children, immunomodulatory drugs, infection, paediatric intensive care unit, sepsis

\section{INTRODUCTION}

Paediatric sepsis is one of the main causes of childhood mortality. ${ }^{1}$ Globally, paediatric severe sepsis and septic shock accounts for $6.2 \%$ to $23.1 \%$ of paediatric intensive care unit (PICU) admissions, and mortality rates can be as high as $21.3 \%$ in North America and Europe to $50.0 \%$ in Asia. ${ }^{2-4}$ Of particular concern are the outcomes in the increasing number of children with significant comorbidities such as malignancy, or those with chronic organ impairment who survive into later years and pose new considerations to the management of severe sepsis and septic shock. ${ }^{5-7}$

Sepsis is a life-threatening organ dysfunction caused by a dysregulated host response to infection. ${ }^{8}$ This definition recognises the role of the host immune response to an infection. Sepsis is thought to be driven by an initial hyper-inflammatory response followed by an immunosuppressive phase. However, recent studies have shown a shift towards a new paradigm, where a prolonged inflammatory and anti-inflammatory state

\footnotetext{
${ }^{1}$ Department of Paediatrics, KK Women's and Children's Hospital, Singapore

${ }^{2}$ Department of Surgery, National University Hospital, Singapore

${ }^{3}$ Center for Quantitative Medicine, Duke-NUS Medical School, Singapore

${ }^{4}$ Children's Intensive Care Unit, Department of Paediatric Subspecialties, KK Women's and Children's Hospital, Singapore

${ }^{5}$ Duke-NUS Medical School, Singapore

Correspondence: Dr Alpha Omega Cheng Jin Lee, KK Women's and Children's Hospital, 100 Bukit Timah Road, Singapore 229899.

Email: alpha.lee@mohh.com.sg
} 


\section{CLINICAL IMPACT}

\section{What is New}

- Our report shows frequent exposure to immunemodulating drugs in children with severe sepsis and septic shock.

- The reactive increase in white cell indices expected during the course of sepsis is absent in children exposed to immune-modulating drugs.

- Exposure to immune-modulating drugs during paediatric severe sepsis and septic shock is associated with greater duration of invasive mechanical ventilation and paediatric intensive care stay.

\section{Clinical Implications}

- Exposure to immune-modulating drugs during paediatric severe sepsis and septic shock is associated with worsened clinical outcomes and warrants further study.

occurring simultaneously is driven by a dysfunctional innate and suppressed adaptive immunity, which together results in persistent organ injury and death..$^{9-11}$ Therefore, it has been theorised that immunotherapy holds promise in modulating the immune system. However, the use of immunotherapy in treating sepsis has been met with mixed results. ${ }^{12,13}$ Recent clinical trials involving corticosteroids showed mixed results regarding mortality and hospitalisation. ${ }^{14,15} \mathrm{~A}$ Cochrane review on intravenous immunoglobulin (IVIG) revealed mortality benefit in adults with sepsis but not in neonates. ${ }^{16}$ Statistically proven mortality benefit has yet to be found with the use of granulocyte-colony stimulating factor (GCSF), interferon-gamma, interleukin-7 and anti-PD 1 (programmed cell death protein 1) in sepsis. ${ }^{17-20}$

While several studies have been conducted in the paediatric setting, these have largely involved limited sample sizes with inconclusive results. ${ }^{21-23}$ Nevertheless, we suspect these therapies are often utilised in the management of paediatric sepsis and septic shock. ${ }^{24}$ In this study, we review cases of paediatric severe sepsis and septic shock in our institution to determine the characteristics of patients who concurrently received immune-modulating drugs, particularly corticosteroids, IVIG and GCSF, and examine their outcomes.

\section{METHODS}

This is a retrospective cohort study conducted in the PICU of KK Women's and Children's Hospital, a university-affiliated tertiary hospital in Singapore. This study was approved by the SingHealth Centralised Institutional Review Board (reference number: 2016/2171) and a waiver of consent was granted.

Patients were identified based on their discharge diagnosis from hospital-wide electronic medical databases. Patients aged 0 to 18 years admitted to the PICU between 1 January 2010 and 31 October 2017 were included upon meeting the diagnostic criteria for paediatric severe sepsis or septic shock as defined by the International Pediatric Sepsis Consensus Conference. ${ }^{25}$ The use of corticosteroids, GCSF, IVIG, plasma exchange or other biologic drugs at the time of PICU admission for sepsis, regardless of indication, was considered to play a direct role on the immune system and categorised in the immunomodulator group. Patients who did not meet the above criteria were placed under the non-immunomodulator group.

Demographic, clinical, microbiological and detailed treatment data were obtained from electronic medical records. Significant chronic comorbidities were defined by the complex chronic conditions list of diseases. ${ }^{26}$ Complex chronic conditions refer to a list of medical conditions that can be reasonably expected to last at least 12 months (unless death intervenes) and to involve either several organ systems or at least 1 organ system severely enough to require specialty paediatric care and probably some period of hospitalisation in a tertiary care centre. ${ }^{26}$ Severity of illness scores, Pediatric Index of Mortality (PIM) 2 score and the Pediatric Logistic Organ Dysfunction (PELOD) score were obtained on PICU admission. ${ }^{27-29}$ Organ dysfunction was defined based on the International Pediatric Sepsis Consensus Conference definition. ${ }^{25}$ Day 1 of severe sepsis and/or septic shock was defined as the day the patient fulfilled the criteria for severe sepsis or septic shock in the PICU. 28-day ventilator-free days (VFD) is defined as days alive and free from invasive mechanical ventilation up to 28 days - this is to account for early deaths. ${ }^{30}$ Similarly, 28-day intensive care unit-free days (IFD) is defined as days alive and discharged from the PICU up to 28 days.

\section{Statistical analysis}

We compared patients in 2 groups: the immunomodulation group and non-immunomodulation group. Clinical characteristics were compared between the 2 groups. Haematological markers across the first 7 days of sepsis including the total leukocyte, lymphocyte, neutrophil and platelet counts were also compared between the 2 groups. The primary outcome of this study was PICU mortality. Secondary outcomes included VFD and IFD. Categorical and continuous variables were expressed as counts (percentages) and median (interquartile range), 
respectively. The Fisher's exact test and Wilcoxon rank sum test were used to compare categorical and continuous variables, respectively. Multivariable logistic regression for the primary outcome was performed with a priori determined covariates: presence of chronic complex conditions, organ dysfunction (summarised as the PELOD score) and the use of immunomodulators. Association from logistic regression was characterised as odds ratio (OR) with corresponding $95 \%$ confidence intervals (CI). The logistic regression was repeated, excluding patients exposed to immunomodulators for autoimmune or immune related indications, as a sensitivity analysis. Secondary outcomes were also analysed with respect to immunomodulator versus nonimmunomodulator groups. Analysis was performed on STATA software version 15.1 (StataCorp, College Station, US). All tests were 2-tailed and $P$ value $<0.05$ was accepted as statistically significant.

\section{RESULTS}

There were 109 patients who met the criteria for paediatric severe sepsis or septic shock (Table 1). Clinical characteristics were similar between the immunomodulator and non-immunomodulator groups in terms of age, presence of complex chronic conditions, PIM2, PELOD scores and source of sepsis on admission. The most common source of sepsis was pneumonia $(59 / 109,54.1 \%)$, followed by gastrointestinal $(16 / 109,14.7 \%)$ and musculoskeletal $(8 / 109,7.3 \%)$ (Table 2). Sepsis from a single aetiologic agent was most commonly bacterial $(28 / 109,25.7 \%)$, followed by viral $(25 / 109,22.9 \%)$. Co-infections were present in $19(17.4 \%)$ patients and no identifiable aetiologic agent was found in 32 (29.4\%).

Immunomodulating therapies, regardless of indications, were used in $54(49.5 \%)$ patients. Systemic corticosteroid was the most common immunomodulator $(47 / 109,43.1 \%)$, followed by IVIG $(16 / 109,14.7 \%)$ and GCSF $(3 / 109,2.8 \%)$. One patient who fulfilled the criteria for severe sepsis also received therapeutic plasma exchange. There were no patients who concurrently received chemotherapy or biologics during the course of sepsis in the PICU. The clinical indications for use of these therapies are summarised in Table 3. The median total white cell count was lower in the group receiving immunomodulators throughout the first 7 days of study (except on day 2, which did not reach statistical significance) (Fig. 1A). The trend of total white cell count was also observed to increase across the 7 days in those without exposure to immunomodulators, but this was not seen in those on immunomodulator group. A similar trend was seen in the absolute neutrophil and lymphocyte counts, especially toward the end of the 7 days (Figs. 1B and 1C). There was no difference in the platelet count over the 7 days of sepsis between the 2 groups (Fig. 1D).

Despite having similar admission characteristics, patients in the immunomodulation group required greater PICU support compared to those in the nonimmunomodulation group, including invasive ventilation $(38 / 54,70.4 \%$ vs $26 / 55,47.3 \% ; P=0.019)$ and inotropes $(41 / 54,75.9 \%$ vs $32 / 55,58.2 \% ; P=0.067)$, though this did not reach statistical significance. Ventilator- and ICU-free days were also reduced in the immunomodulator group (20 [0-28] vs 25 [12-28]; $P=0.038$ and 15 [0-24] vs 22 (9-26); $P=0.024$, respectively). In this sepsis cohort, a total of 31 deaths $(28.4 \%)$ occurred. PICU mortality was higher among patients receiving immunomodulating therapy compared to patients who did not receive it $(20 / 54$ [37.0\%] vs $11 / 55$ [20.0\%]; $P=0.058$ ), although this was not statistically significant (Table 1). Significantly greater number of patients with malignancy received immunomodulator therapy as compared to those who did not (14/54 [25.9\%] vs $3 / 55$ [5.5\%]; $P=0.004)$. After accounting for complex chronic conditions and admission organ dysfunction (PELOD score), exposure to immunomodulator therapy was not associated with an increase in PICU mortality (adjusted odds ratio 1.90 (95\% confidence interval 0.72-5.01); $P=0.193$ ) (Table 4). In the sensitivity analysis excluding patients exposed to immunomodulators for autoimmune or immune related indications, the results were similar.

\section{DISCUSSION}

Our report shows frequent exposure to immunomodulating drugs in children with severe sepsis and septic shock. This group of children seem to require greater PICU support including mechanical ventilation and inotropes. After adjusting for complex chronic conditions and admission organ dysfunction, immunomodulators were associated with an almost 2-fold increased mortality, though this did not achieve statistical significance due to the small cohort size. A reactive and expected increase in white cell indices was observed in children with severe sepsis and septic shock. However, this was absent in those receiving immunomodulators.

The use of immunomodulators may inherently bias towards a group of patients with underlying immunological defects (e.g. malignancies, chemotherapy and autoimmune disease), though in the logistic regression model, these conditions were accounted for. In our cohort, 17 patients had malignancy and 3 patients had haematological disease, for which 14 patients and 
Table 1. Characteristics of patients who received immune modulating therapy

\begin{tabular}{|c|c|c|c|c|}
\hline & $\begin{array}{l}\text { Immune modulation } \\
\qquad(\mathrm{n}=54)\end{array}$ & $\begin{array}{l}\text { No immune modulation } \\
\qquad(\mathrm{n}=55)\end{array}$ & All $(N=109)$ & $P$ value \\
\hline Age, median (IQR), years & $9.3(1.4-13.0)$ & $9.4(0.4-13.1)$ & $9.4(2.4-13.0)$ & 0.952 \\
\hline Male sex, no. (\%) & $22(40.7)$ & $29(52.7)$ & $51(46.8)$ & 0.251 \\
\hline Weight, median (IQR), kg & $24.7(12.7-37.8)$ & $24.4(11.2-40.0)$ & $24.4(11.5-40.0)$ & 0.971 \\
\hline CCC, no. (\%) & $31(57.4)$ & $23(41.8)$ & $54(49.5)$ & 0.127 \\
\hline Malignancy & $14(25.9)$ & $3(5.5)$ & $17(15.6)$ & 0.004 \\
\hline Haematology-Immunology & $2(3.7)$ & $1(1.8)$ & $3(2.8)$ & 0.618 \\
\hline PIM 2, median (IQR) & $3.3(1.3-7.1)$ & $3.5(1.2-9.6)$ & $3.4(1.3-8.9)$ & 0.854 \\
\hline PELOD, median (IQR) & $13(11-22)$ & $11(10-21)$ & $12(10-21)$ & 0.123 \\
\hline Source of sepsis, no. (\%) & & & & 0.603 \\
\hline Pneumonia & $26(48.2)$ & $31(56.4)$ & $57(52.3)$ & \\
\hline Central nervous system & $4(7.4)$ & $3(5.5)$ & $7(6.4)$ & \\
\hline Musculoskeletal & $6(11.1)$ & $2(3.6)$ & $8(7.3)$ & \\
\hline Gastrointestinal & $7(13.0)$ & $10(18.1)$ & $17(15.6)$ & \\
\hline Blood stream & $4(7.4)$ & $2(3.6)$ & $6(5.5)$ & \\
\hline Others & $7(13.0)$ & $7(12.7)$ & $14(12.8)$ & \\
\hline Bacteraemia, no. (\%) & $12(22.6)$ & $11(19.6)$ & $23(21.2)$ & 0.815 \\
\hline Source control, no. (\%) & $4(7.4)$ & $7(12.7)$ & $11(10.1)$ & 0.527 \\
\hline Inotropes, no. (\%) & $41(75.9)$ & $32(58.2)$ & $73(67.0)$ & 0.067 \\
\hline Non-invasive ventilation, no. (\%) & $13(24.1)$ & $18(32.7)$ & $3128.4)$ & 0.397 \\
\hline Invasive ventilation, no. (\%) & $38(70.4)$ & $26(47.3)$ & $64(58.7)$ & 0.019 \\
\hline Duration of invasive ventilation, no. (\%), days & $3(0,6)$ & $0(0,4)$ & $2(0,5)$ & 0.134 \\
\hline VFD, median (IQR), days & $19.5(0-28)$ & $25(12-28)$ & $23(0-28)$ & 0.038 \\
\hline Multiorgan dysfunction, no. (\%) & $51(94.4)$ & $46(83.6)$ & $97(89.0)$ & 0.124 \\
\hline ECMO, no. $(\%)$ & $6(11.1)$ & $3(5.5)$ & $9(8.3)$ & 0.320 \\
\hline Mortality, no. (\%) & $20(37.0)$ & $11(20.0)$ & $31(28.4)$ & 0.058 \\
\hline ICU LOS, median (IQR), days & $5(2-11)$ & $3(1-7)$ & $4(2-9)$ & 0.076 \\
\hline IFD, median (IQR), days & $15(0-24)$ & $22(9-26)$ & $21(0-25)$ & 0.024 \\
\hline Hospital LOS, median (IQR), days & $15(7-29)$ & $10(5-19)$ & $12(6-22)$ & 0.146 \\
\hline
\end{tabular}

CCC: complex chronic conditions; ECMO: extra-corporeal membrane oxygenation; ICU: intensive care unit; IFD: 28-day intensive care unit-free days; IQR: interquartile range; LOS: length of stay; PELOD: Pediatric Logistic Organ Dysfunction; PIM: Pediatric Index of Mortality; VFD: 28-day ventilatorfree days

Categorical variables are reported as count (percentages) and continuous variables are reported as median (IQR)

$P$ values in bold are significant

2 patients, respectively received immunomodulator therapy. In the same way, patients with significant organ dysfunction at PICU admission who were likely to bias the outcome negatively were also accounted for. Nevertheless, our study seems to suggest that immunomodulator therapy was associated with an almost 2-fold increase in mortality, although this was statistically not significant. A prospective study with a larger sample size would provide a clearer association and determination of statistical significance. 
Table 2. Aetiologic agents involved in paediatric severe sepsis and septic shock

\begin{tabular}{|c|c|c|c|c|c|c|c|c|}
\hline \multirow[b]{2}{*}{ Source of sepsis } & \multirow[b]{2}{*}{$\begin{array}{l}\text { None } \\
(n=32)\end{array}$} & \multicolumn{3}{|c|}{ Single aetiologic agent } & \multicolumn{4}{|c|}{ Co-infection } \\
\hline & & $\begin{array}{c}\text { Bacteria } \\
(n=28)\end{array}$ & $\begin{array}{c}\text { Virus } \\
(n=25)\end{array}$ & $\begin{array}{l}\text { Fungi } \\
(n=5)\end{array}$ & $\begin{array}{l}\text { Bacteria and } \\
\text { virus }(n=9)\end{array}$ & $\begin{array}{l}\text { Bacterial and } \\
\text { fungi }(n=3)\end{array}$ & $\begin{array}{c}\text { Virus and } \\
\text { fungi }(n=6)\end{array}$ & $\begin{array}{r}\text { Bacteria, virus } \\
\text { and fungi }(n=1)\end{array}$ \\
\hline Pneumonia & 15 & 13 & 16 & 3 & 4 & 1 & 6 & 1 \\
\hline Genito-urinary & 0 & 1 & 0 & 0 & 1 & 0 & 0 & 0 \\
\hline Central nervous system & 0 & 2 & 4 & 0 & 1 & 0 & 0 & 0 \\
\hline Musculoskeletal & 4 & 4 & 0 & 0 & 0 & 0 & 0 & 0 \\
\hline Gastrointestinal & 5 & 2 & 3 & 1 & 3 & 2 & 0 & 0 \\
\hline Blood stream & 0 & 6 & 0 & 0 & 0 & 0 & 0 & 0 \\
\hline Others & 2 & 0 & 2 & 1 & 0 & 0 & 0 & 0 \\
\hline
\end{tabular}

Table 3. Indications for immune-modulating therapy

\begin{tabular}{|c|c|c|}
\hline Immune modulating therapy & Indication & Patients, no. \\
\hline \multirow{4}{*}{$\begin{array}{l}\text { Systemic corticosteroids } \\
(\mathrm{n}=47)\end{array}$} & Septic shock & 26 \\
\hline & $\begin{array}{l}\text { Respiratory disease } \\
\text { Pulmonary hemosiderosis } \\
\text { Pulmonary fibrosis } \\
\text { Asthma } \\
\text { ARDS } \\
\text { Airway oedema }\end{array}$ & 11 \\
\hline & Premedication for blood transfusion (or other drugs) & 5 \\
\hline & $\begin{array}{l}\text { Others } \\
\text { Takayasu arteritis } \\
\text { Hypoglycaemia } \\
\text { Acute necrotising encephalomyelitis } \\
\text { Autoimmune haemolysis } \\
\text { Resistant mycoplasma infection }\end{array}$ & 5 \\
\hline \multirow[t]{3}{*}{$\begin{array}{l}\text { IVIG } \\
(\mathrm{n}=16)\end{array}$} & $\begin{array}{l}\text { Infection } \\
\text { Severe sepsis } \\
\text { Influenza encephalitis } \\
\text { Toxic shock syndrome } \\
\text { Myocarditis } \\
\text { Adenovirus infection }\end{array}$ & 10 \\
\hline & $\begin{array}{l}\text { Immunoglobulin replacement } \\
\text { Post HSCT } \\
\text { Primary immunodeficiency } \\
\text { Haemophagocytic histiocytosis }\end{array}$ & 3 \\
\hline & $\begin{array}{l}\text { Autoimmune disease } \\
\text { Takayasu arteritis } \\
\text { Kawasaki disease } \\
\text { Autoimmune haemolysis }\end{array}$ & 3 \\
\hline $\begin{array}{l}\text { GSCF } \\
(n=3)\end{array}$ & $\begin{array}{l}\text { Severe neutropenic sepsis } \\
\text { Post-chemotherapy } \\
\text { Haemophagocytic histiocytosis }\end{array}$ & 3 \\
\hline Therapeutic plasma exchange $(n=1)$ & Autoimmune haemolysis & 1 \\
\hline
\end{tabular}

ARDS: acute respiratory distress syndrome; GCSF: granulocyte-colony stimulating factor; HSCT: haematopoietic stem cell transplant; IVIG: intravenous immunoglobulin 
Fig. 1. Trend of haematological markers across first 7 days of sepsis in patients with and without immunomodulator therapy.

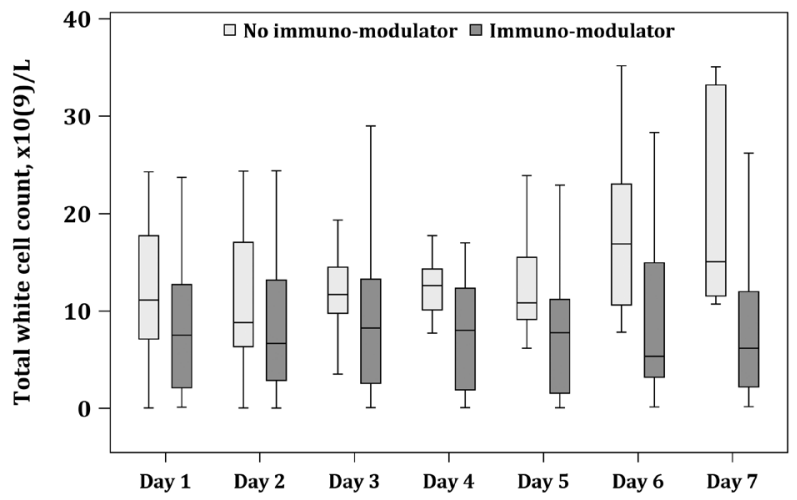

(A) Total white cell count trend.

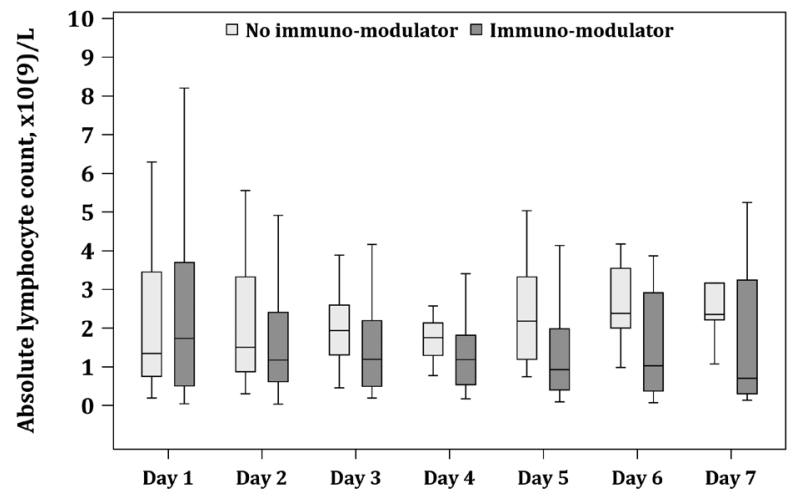

(C) Absolute leukocyte count trend.

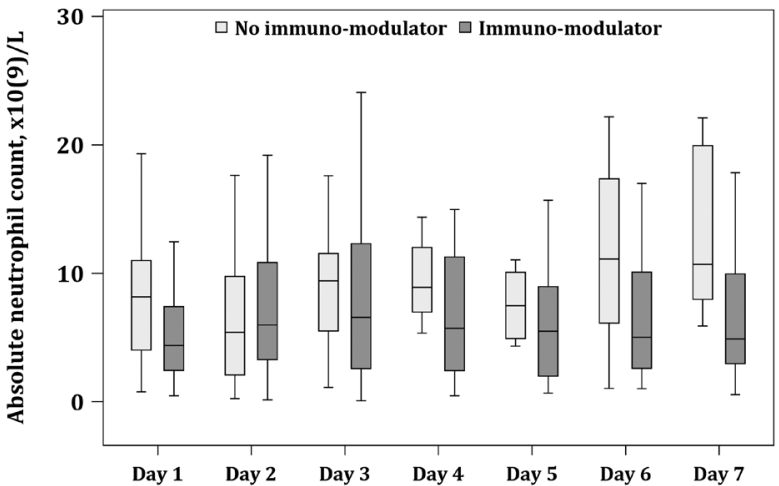

(B) Absolute neutrophil count trend.

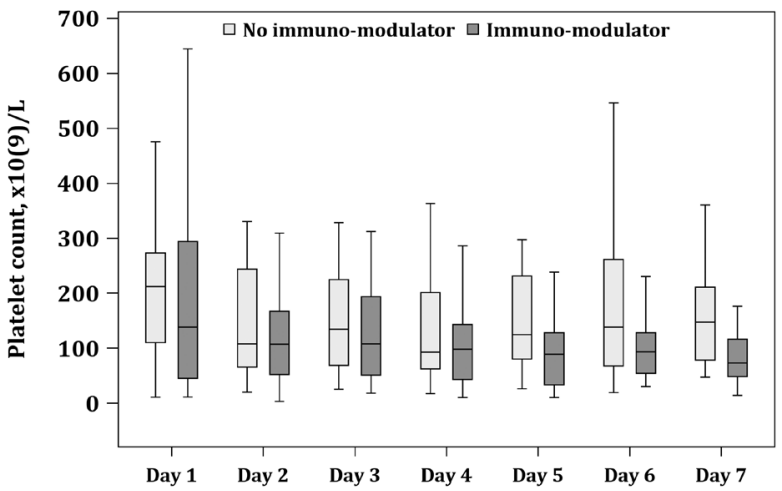

(D) Platelet count trend.

Table 4. Multivariable logistic regression for paediatric intensive care unit mortality

\begin{tabular}{|c|c|c|c|c|c|c|}
\hline \multirow[t]{2}{*}{ Covariate } & \multicolumn{3}{|c|}{ Univariate } & \multicolumn{3}{|c|}{ Multivariable } \\
\hline & OR & $95 \%$ CI & $P$ value & OR & $95 \%$ CI & $P$ value \\
\hline $\mathrm{CCC}$ & 2.86 & $1.19-6.88$ & 0.019 & 2.16 & $0.80-5.82$ & 0.127 \\
\hline PELOD & 1.11 & $1.05-1.16$ & $<0.001$ & 1.10 & $1.05-1.16$ & $<0.001$ \\
\hline Immuno-modulation & 2.35 & $0.99-5.57$ & 0.051 & 1.90 & $0.72-5.01$ & 0.193 \\
\hline
\end{tabular}

Replacing "CCC" with "malignancy" generated similar results

CCC: complex chronic conditions; CI: confidence interval; OR: odds ratio; PELOD: Pediatric Logistic Organ Dysfunction

The majority of immunomodulator use consisted of systemic corticosteroids (47/54, 87.0\%). Though indications for the use of corticosteroids, in our cohort, were largely adrenal suppression and respiratory, corticosteroids have myriad effects on other systems and have been associated with hyperglycemia, impaired wound healing, hospital acquired infections, as well as increased organ failure and mortality. ${ }^{31,32}$ In addition, corticosteroids also contribute to the development of myopathy ${ }^{33,34}$ and can prolong the duration of invasive ventilation and hospitalisation. ${ }^{35}$ These negative effects may have contributed as a cause for the increased mortality, and decreased VFD and IFD observed in our cohort, however, due to the retrospective design, only an association can be made. The Stress Hydrocortisone in Pediatric Septic Shock (SHIPSS) trial specifically seeks to determine if adjunctive hydrocortisone will significantly reduce the proportion of children with 
septic shock from death or subsequent poor quality of life (clinicaltrial.gov NCT03401398). The outcome of this randomised controlled, double-blinded study is anticipated to provide a definitive answer to the current gap in knowledge on the effect of corticosteroids in sepsis.

Mortality benefit was found in adult patients with sepsis who were treated with IVIG. ${ }^{36}$ These effects may be attributed to IVIG's role in immunoglobulin replacement and its potential effects on B cells, T cells, antibodies, complement pathways and cytokines in adult neuromuscular disorders and immune neuropathies. ${ }^{37}$ However, a meta-analysis evaluating the effects of IVIG in neonatal infections found no mortality benefit. ${ }^{38}$ Our paediatric cohort may not be directly comparable to either the adult nor neonatal population; however, our data suggest a tendency to poorer outcomes in patients who receive drugs that have an immunomodulating effect including IVIG. A reduction in the overall white cell count has also been described in patients from other studies receiving IVIG consistent with a reduction in both absolute neutrophil count and absolute lymphocyte count (ALC); however the mechanism was described as multifactorial ${ }^{39,40}$ and not fully understood. ${ }^{22}$ The reduction in ALC may also be contributed by the suppressive effects of corticosteroids on ALC. ${ }^{41,42}$ The overall reduction of white cell differentials may also be a reflection of the biphasic sepsis response, whereby patients who survive the initial hyper-inflammatory phase enter a protracted hypo-inflammatory phase characterised by persistent inflammation and immune suppression. ${ }^{43,44}$ Immune cell depletion in this phase is driven by caspase-mediated apoptosis. ${ }^{45}$ Compromise in innate defences ${ }^{46,47}$ and $\mathrm{T}$ cell exhaustion ${ }^{48}$ contribute to a state of malfunctional immune tolerance and susceptibility to further infections and mortality. ${ }^{44}$

There are several limitations in this study's findings. Firstly, due to the small sample size, we could not establish an association between mortality and immunomodulation therapy despite an almost 2-fold increase in mortality, nor perform additional subanalysis (e.g. to examine each immune-modulator therapy separately). The current sample size of 109 achieves only $66 \%$ power to detect a difference in mortality of $20 \%$ between the 2 groups, using the two-sided Fisher's exact test and assuming a significance level as $5 \%$. A prospective study design with a larger cohort $(\mathrm{n}=182)$ is recommended to address these limitations and adequately power the study $(\beta=80 \%)$ to detect a mortality difference.

We also were unable to determine causation between the use of immunomodulation and worsened primary and secondary outcomes given the retrospective nature of this study. Indications for these immunomodulation therapies were also heterogenous and physician dependent. Lastly, other important variables such as malnutrition that may have affected the immune system were not accounted for.

\section{CONCLUSION}

Exposure to immune-modulating drugs during paediatric severe sepsis and septic shock is associated with higher use of invasive ventilation and less IFD and VFD. A reactive and expected increase in white cell indices was observed during the course of sepsis; however, this was absent in children receiving immunomodulators. A prospective study is recommended to further determine the effectiveness of immunemodulating therapy on primary and secondary outcomes in severe sepsis and septic shock in the paediatric population.

\section{Disclosures}

There are no affiliations or financial involvement with any commercial organisations in this study. An abstract of the current work has been presented at the 6th SG-ANZICS Asia Pacific Intensive Care Forum 2019.

\section{REFERENCES}

1. Rudd KE, Johnson SC, Agesa KM, et al. Global, regional, and national sepsis incidence and mortality, 1990-2017: analysis for the Global Burden of Disease Study. Lancet 2020;395:200-11.

2. Tan B, Wong JJ, Sultana R, et al. Global Case-Fatality Rates in Pediatric Severe Sepsis and Septic Shock: A Systematic Review and Meta-analysis. JAMA Pediatr 2019;173:352-62.

3. Fleischmann-Struzek C, Goldfarb DM, Schlattmann P, et al. The global burden of paediatric and neonatal sepsis: a systematic review. Lancet Respir Med. 2018;6:223-30.

4. Wong JJ, Ho SX, Lee AOC, et al. Positive Fluid Balance is Associated with Poor Clinical Outcomes in Paediatric Severe Sepsis and Septic Shock. Ann Acad Med Singap 2019;48:290-7.

5. Esper AM, Moss M, Lewis CA, et al. The role of infection and comorbidity: Factors that influence disparities in sepsis. Crit Care Med 2006;34:2576-82.

6. Adamson PC. Improving the outcome for children with cancer: Development of targeted new agents. CA Cancer J Clin 2015;65: 212-20.

7. Boneva RS, Botto LD, Moore CA, et al. Mortality associated with congenital heart defects in the United States: trends and racial disparities, 1979-1997. Circulation 2001;103:2376-81.

8. Singer M, Deutschman CS, Seymour CW, et al. The Third International Consensus Definitions for Sepsis and Septic Shock (Sepsis-3). JAMA 2016;315:801-10.

9. Boomer JS, To $\mathrm{K}$, Chang $\mathrm{KC}$, et al. Immunosuppression in patients who die of sepsis and multiple organ failure. JAMA 2011;306: 2594-605. 
10. Rittirsch D, Flierl MA, Ward PA. Harmful molecular mechanisms in sepsis. Nat Rev Immunol 2008;8:776-87.

11. Xiao W, Mindrinos MN, Seok J, et al. A genomic storm in critically injured humans. J Exp Med 2011;208:2581-90.

12. Lo AH, Kee AC, Li A, et al. Controversies in Sepsis ManagementWhat is the Way Forward? Ann Acad Med Singap 2020;49:661-8.

13. Chong SL, Ong GY, Venkataraman A, et al. The golden hours in paediatric septic shock--current updates and recommendations. Ann Acad Med Singap 2014;43:267-74

14. Annane D, Renault A, Brun-Buisson C, et al. Hydrocortisone plus Fludrocortisone for Adults with Septic Shock. N Engl J Med 2018;378:809-18.

15. Venkatesh B, Finfer S, Cohen J, et al. Adjunctive Glucocorticoid Therapy in Patients with Septic Shock. N Engl J Med 2018; 378:797-808.

16. Alejandria MM, Lansang MA, Dans LF, et al. Intravenous immunoglobulin for treating sepsis, severe sepsis and septic shock. Cochrane Database Syst Rev 2013:CD001090.

17. Vignon P, Laterre PF, Daix T, et al. New Agents in Development for Sepsis: Any Reason for Hope? Drugs 2020;80:1751-61.

18. Payen D, Faivre V, Miatello J, et al. Multicentric experience with interferon gamma therapy in sepsis induced immunosuppression. A case series. BMC Infect Dis 2019;19:931.

19. Francois B, Jeannet R, Daix $\mathrm{T}$, et al. Interleukin-7 restores lymphocytes in septic shock: the IRIS-7 randomized clinical trial. JCI Insight 2018;3:e98960.

20. Bo L, Wang F, Zhu J, et al. Granulocyte-colony stimulating factor (G-CSF) and granulocyte-macrophage colony stimulating factor (GM-CSF) for sepsis: a meta-analysis. Crit Care 2011;15:R58.

21. Carr R, Modi N, Dore C. G-CSF and GM-CSF for treating or preventing neonatal infections. Cochrane Database Syst Rev 2003;2003:CD003066

22. Wong PH, White KM. Impact of Immunoglobulin Therapy in Pediatric Disease: a Review of Immune Mechanisms. Clin Rev Allergy Immunol 2016;51:303-14.

23. Zimmerman JJ, Williams MD. Adjunctive corticosteroid therapy in pediatric severe sepsis: observations from the RESOLVE study. Pediatr Crit Care Med 2011;12:2-8.

24. Mathias B, Mira JC, Larson SD. Pediatric sepsis. Curr Opin Pediatr 2016;28:380-7.

25. Goldstein B, Giroir B, Randolph A, et al. International pediatric sepsis consensus conference: definitions for sepsis and organ dysfunction in pediatrics. Pediatr Crit Care Med 2005;6:2-8

26. Edwards JD, Houtrow AJ, Vasilevskis EE, et al. Chronic conditions among children admitted to U.S. pediatric intensive care units: their prevalence and impact on risk for mortality and prolonged length of stay. Crit Care Med 2012;40:2196-203.

27. Leteurtre S, Duhamel A, Grandbastien B, et al. Paediatric logistic organ dysfunction (PELOD) score. Lancet 2006;367:897.

28. Wong JJ, Hornik CP, Mok YH, et al. Performance of the Paediatric Index of Mortality 3 and Paediatric Logistic Organ Dysfunction 2 Scores in Critically Ill Children. Ann Acad Med Singap 2018; 47:285-90

29. Slater A, Shann F, Pearson G. PIM2: a revised version of the Paediatric Index of Mortality. Intensive Care Med 2003;29:278-85.
30. Yehya N, Harhay MO, Curley MAQ, et al. Reappraisal of Ventilator-Free Days in Critical Care Research. Am J Respir Crit Care Med 2019;200:828-36.

31. Schacke H, Docke WD, Asadullah K. Mechanisms involved in the side effects of glucocorticoids. Pharmacol Ther 2002;96:23-43.

32. Yung M, Wilkins B, Norton L, et al. Glucose control, organ failure, and mortality in pediatric intensive care. Pediatr Crit Care Med 2008;9:147-52.

33. Bercker S, Weber-Carstens S, Deja M, et al. Critical illness polyneuropathy and myopathy in patients with acute respiratory distress syndrome. Crit Care Med 2005;33:711-5.

34. Lacomis D, Giuliani MJ, Van Cott A, et al. Acute myopathy of intensive care: clinical, electromyographic, and pathological aspects. Ann Neurol 1996;40:645-54.

35. Amaya-Villar R, Garnacho-Montero J, Garcia-Garmendia JL, et al. Steroid-induced myopathy in patients intubated due to exacerbation of chronic obstructive pulmonary disease. Intensive Care Med 2005;31:157-61

36. Yang Y, Yu X, Zhang F, et al. Evaluation of the Effect of Intravenous Immunoglobulin Dosing on Mortality in Patients with Sepsis: A Network Meta-analysis. Clin Ther 2019;41:1823-38.e4.

37. Hartung HP. Advances in the understanding of the mechanism of action of IVIg. J Neurol 2008;255(Suppl 3):3-6.

38. Alomran A. Intravenous Immunoglobulin Doesn't Decrease Mortality for Suspected or Proven Sepsis in the Neonate. J Clin Neonatol 2013;2:163-5.

39. Cicha A, Fischer MB, Wesinger A, et al. Effect of intravenous immunoglobulin administration on erythrocyte and leucocyte parameters. J Eur Acad Dermatol Venereol 2018;32:1004-10.

40. Koffman BM, Dalakas MC. Effect of high-dose intravenous immunoglobulin on serum chemistry, hematology, and lymphocyte subpopulations: assessments based on controlled treatment trials in patients with neurological diseases. Muscle Nerve 1997;20:1102-7.

41. Fauci AS, Dale DC, Balow JE. Glucocorticosteroid therapy: mechanisms of action and clinical considerations. Ann Intern Med 1976;84:304-15

42. Heming N, Sivanandamoorthy S, Meng P, et al. Immune Effects of Corticosteroids in Sepsis. Front Immunol 2018;9:1736.

43. Nedeva C, Menassa J, Puthalakath H. Sepsis: Inflammation Is a Necessary Evil. Front Cell Dev Biol 2019;7:108.

44. Hotchkiss RS, Monneret G, Payen D. Sepsis-induced immunosuppression: from cellular dysfunctions to immunotherapy. Nat Rev Immunol 2013;13:862-74.

45. Hotchkiss RS, Osmon SB, Chang KC, et al. Accelerated lymphocyte death in sepsis occurs by both the death receptor and mitochondrial pathways. J Immunol 2005;174:5110-8.

46. Huang X, Venet F, Wang YL, et al. PD-1 expression by macrophages plays a pathologic role in altering microbial clearance and the innate inflammatory response to sepsis. Proc Natl Acad Sci USA 2009; 106:6303-8

47. Forel JM, Chiche L, Thomas G, et al. Phenotype and functions of natural killer cells in critically-ill septic patients. PLoS One 2012;7:e50446.

48. Condotta SA, Khan SH, Rai D, et al. Polymicrobial Sepsis Increases Susceptibility to Chronic Viral Infection and Exacerbates CD8+ T Cell Exhaustion. J Immunol 2015;195:116-25. 